\title{
Contradictions between corporate and state sectoral management in russian regions' oil industry: digital solutions
}

\author{
Dmitry Rodnyansky, ${ }^{1, *}$, Aliaksei Bykau ${ }^{2}$, Sergey Manasyan ${ }^{3}$, Yuri Basharimov ${ }^{4}$, and Maxim \\ $\operatorname{Evsin}^{4}$ \\ ${ }^{1}$ Kazan federal university, 18, Kremlevskaya str, Kazan, Russia \\ ${ }^{2}$ Belarus state economic university, Minsk, Belarus \\ ${ }^{3}$ The Russian presidential academy of national economy and public administration, Moscow, Russia \\ ${ }^{4}$ Financial University under the Government of the Russian Federation, Lipetsk branch, Lipetsk, \\ Russia
}

\begin{abstract}
Currently, the key and budget-forming sector of the Russian economy is still the oil industry, which includes the production, processing, transportation and sale of oil and oil products. The share of the oil industry in the country's GDP amounted to above $40 \%$, and, taking into account the petrochemical and manufacturing industries, exceeds $50 \%$. In this aspect, an important task is to study the institutional environment of the operation of enterprises and organizations of the oil industry, as well as the mechanisms and tools of state sectoral management, because not only the activities of individual companies, corporations and enterprises, but also the level of socio-economic development of the country as a whole. The main forms of state participation in the regulation of such industries remain direct ownership of shares, including a controlling stake or "golden share", delegation of government representatives to corporate boards of directors, as well as the creation of various forms of organizations with state participation. At the same time, there are a number of contradictions between the state, economic entities of the oil industry and public and expert organizations, which are expressed in different interpretations of short-term and long-term goals, the presence of not always coordinated concepts and strategies for the development of individual industries and areas, inconsistency of a number of state programs, projects, etc. These contradictions lead to a decrease in the efficiency of the system of state regulation of strategic sectors of the economy, which is expressed in a significant lag in labor productivity.
\end{abstract}

\section{Introduction}

One of the most discussed problems in recent years is the search for working tools and mechanisms for organizing the effective functioning of private business and companies with state participation. After the large-scale crisis of 2008-2009, as well as a consequence of the

\footnotetext{
* Corresponding author: drodnyansky@ gmail.com
} 
outbreak of the Covid-19 pandemic, many private companies came under full or partial state control. Thus, the state, on the one hand, acts as a business owner, and on the other, as a regulator. Obviously, such a situation causes certain contradictions and problems.

One of the ways to solve the declared contradictions is to use the concept of new public management, which has become in demand in many European states. The essence of the concept of the new public administration is to encourage the redistribution of powers between different levels of government, the division of responsibility for the purchase of utilities, the conclusion of agreements with the private sector on the production of public goods by the latter, the shifting of part of the infrastructure costs to the private sector, namely, closer interaction between business and political authorities at various levels.

This article examines issues related to the emergence of contradictions between public authorities and business, both at the federal and regional levels. The paper analyzes the consequences of the existence of such contradictions, as well as put forward proposals for improving the interaction of business structures and government bodies to increase the efficiency of their work.

Recently, several multidirectional trends can be observed in the world. On the one hand, in a number of states, the private sector is expanding, the number of small enterprises and individual entrepreneurs, or the so-called self-employed, is growing. On the other hand, there is a clear tendency of globalization of state-owned companies and their transition to the status of transnational state corporations. This trend is typical not only for developing countries, such as China, Russia, Brazil, India, but also for countries with developed economies Norway, France, Italy, South Korea. The largest number of transnational state corporations is observed in the energy sector, namely in the nuclear industry, oil production and processing, transportation of oil, gas and oil products [2, 4, 6, 7, 9].

Summarizing the various approaches to the analysis of companies with state participation, we can conclude that the creation of such structures is always based on at least two motives - economic and political. In each specific state at different times one or the other motive may prevail, but, as a rule, these two factors are combined $[1,3,5,8,10]$.

In our research, we consider the contradictions arising from, on the one hand, the growth of the role of the state in the economy of a number of states, and, on the other hand, the need to carry out a regulatory function in the face of aggravated geopolitical challenges, political turbulence and the consequences of the covid pandemic. The purpose of this study is to identify contradictions between the systems of state sectoral and corporate governance of the oil industry in the regions, as well as to develop proposals to overcome these contradictions.

\section{Methods}

Analysis of long-term concepts and strategies for the development of the Russian oil industry and comparison with the public policy documents of the country's largest oil companies demonstrates the existence of fundamental contradictions between the indicated subjects of the economic system. Moreover, such contradictions can arise between the state even with companies in which the state itself owns more than $51 \%$ of the shares. A similar situation arises due to the presence of a different planning horizon for socio-economic processes, mismatched indicators for assessing the effectiveness of the leaders of large corporations and civil servants, the opposite principles of the functioning of exchanges and the state apparatus, as well as different macroeconomic conditions that contribute to the development of the state and society in general and private, semi-state and state-owned companies in particular. 


\section{Results and discussion}

First, the contradictions include the different views of these subjects on key macroeconomic indicators. Thus, representatives of the oil industry are interested in a weak national currency, since they receive the bulk of their revenues from exports, and the costs are incurred in the national currency. Thus, a weak national currency increases the international competitiveness of Russian oil companies. In turn, the state is interested in maintaining macroeconomic stability and a relatively strong national currency, since otherwise the real incomes of the population decrease.

Secondly, the state is aimed primarily at achieving stability in the strategic perspective, planning is carried out for the long term. In certain periods of recent history, the state was focused on tactical management of the oil industry in the face of a federal budget deficit and the need to finance social budget items. However, with the introduction of a new budgetary rule, as well as the formation of the National Wealth Fund, the actions of the state in the world oil and oil products market began to be of a longer-term, strategic nature. The rationale for this policy can also be interaction with the OPEC countries and the latest refusal to reduce oil production in order to increase the oil price short-term. Hired managers of corporations are aimed at obtaining good financial results in the short term, since their achievement depends not only on the income of managers, but also on the prospects for further work in the corporation. It is for this reason that in the corporate world situations often arise with incorrect reflection of financial indicators in the reporting, which periodically leads to the initiation of high-profile criminal cases.

Third, corporations, more than the state, are focused on increasing the level of labor productivity. Moreover, often this increase in productivity occurs due to the optimization of the number of jobs, depriving employees, raising plans and other non-market methods. For the state, social stability in a particular region comes to the fore, the creation of new ones and at least the absence of job cuts. For this reason, the government does not welcome such radical measures to increase statistical labor productivity.

Fourth, the Russian Federation is the world leader in the presence of so-called hard-torecover oil reserves. Until recently, issues related to hard-to-recover oil reserves caused many controversies and disputes between companies and business representatives. Currently, there are a number of tax and administrative incentives for companies involved in the production of hard-to-recover oil reserves, but some controversy in this area still remains. The task of the state in this area is to create conditions for the maximum possible development of all existing fields in order to extend the period of active oil production and receive oil revenues. The task of the oil companies is to increase the profitability of such production, and if this is not possible, to freeze the fields and move to more profitable areas of oil production.

One of the most fundamental contradictions between business and government is the issue of business participation in social projects and public life of a region, municipality or community. Until recently, any corporate social responsibility was perceived solely as an imposed condition for further development. Business perceived this exclusively as an additional social burden. In recent years, the social responsibility of business has gradually become voluntary and serves as an indicator of the modernity and advanced views of corporate management.

At the same time, it is the constant and effective interaction of business, government and civil society in the broadest sense of the word that can serve as the mechanism that is capable, if not to resolve the contradictions described above, but to minimize them and find a compromise acceptable to all actors.

So, at present, despite the development of social networks and new forms of interaction, there is an information vacuum with regard to the design, development and implementation of large projects implemented by the state and oil companies. And these projects often have 
a significant impact on the lives of people in entire regions. On the one hand, important social projects and initiatives are discussed at closed meetings in regional and municipal administrations, where business representatives are often not invited. In turn, oil companies develop their strategies in the context of basic industry documents and without considering the needs of the local community. As a result, there is a certain imbalance in the announced plans for the development of companies and strategies for the development of territories.

To solve this problem, the author proposed a methodology that involves the creation of regional councils for intersectoral interaction in the oil industry. This council will reconcile the needs of the local community, various environmental and human rights public organizations with the interests of business structures, taking into account the requirements of the law and the implementation of all necessary regulations by the state. On the site of such a council for intersectoral interaction, an assessment of the regulatory impact of various projects or regulations can be carried out not only on the part of state authorities, which is now being trumpeted by legislation, but also on the part of the expert, scientific and professional community. The pluralism of opinions will allow for a more detailed study of all problematic issues in the implementation of various projects, as well as find solutions that are more effective from a social point of view, which will lead to an increase in social stability and satisfaction of the population both with the system of state and municipal administration and business. The methodology, including the creation of regional councils for intersectoral interaction, is shown in Fig. 1.

In the process of interaction, the members of the Council for Intersectoral cooperation go through a number of stages, including the coordination of goals, restrictions, analysis of risks and consequences of the impact of the project on the region, business structures and nonprofit organizations:

1. Formation of council members on intersectoral interaction for a specific project;

2. Presentation by oil industry business structures of plans for the implementation of projects that have an impact on social infrastructure;

3. Submission by the regional administration of existing restrictions of a regulatory, economic, organizational nature;

4. Presentation by the regional administration of possible areas of mutually beneficial interaction during the implementation of the project;

5. Presentation by the expert community of restrictions and risks in the implementation of the specified project;

6. Assessment of the impact of the project on the development of the territory, social infrastructure, ecology and related industries by the responsible units of the regional administration;

7. Assessment of the impact of the project on the development of the territory, social infrastructure, ecology and related industries by public organizations, the expert community;

8. Presentation of the results of independent impact assessments at the meeting of the regional council on intersectoral interaction;

9. Transformation of technical specifications and business plan for the project implementation;

10. Acceptance of the agreed draft with amendments and its implementation;

11. Submission of a report on the implementation of the project, indicating the costs of implementation by the business structures of the oil industry and the regional administration; presentation of all other forms of compensation to business structures for project implementation costs. 

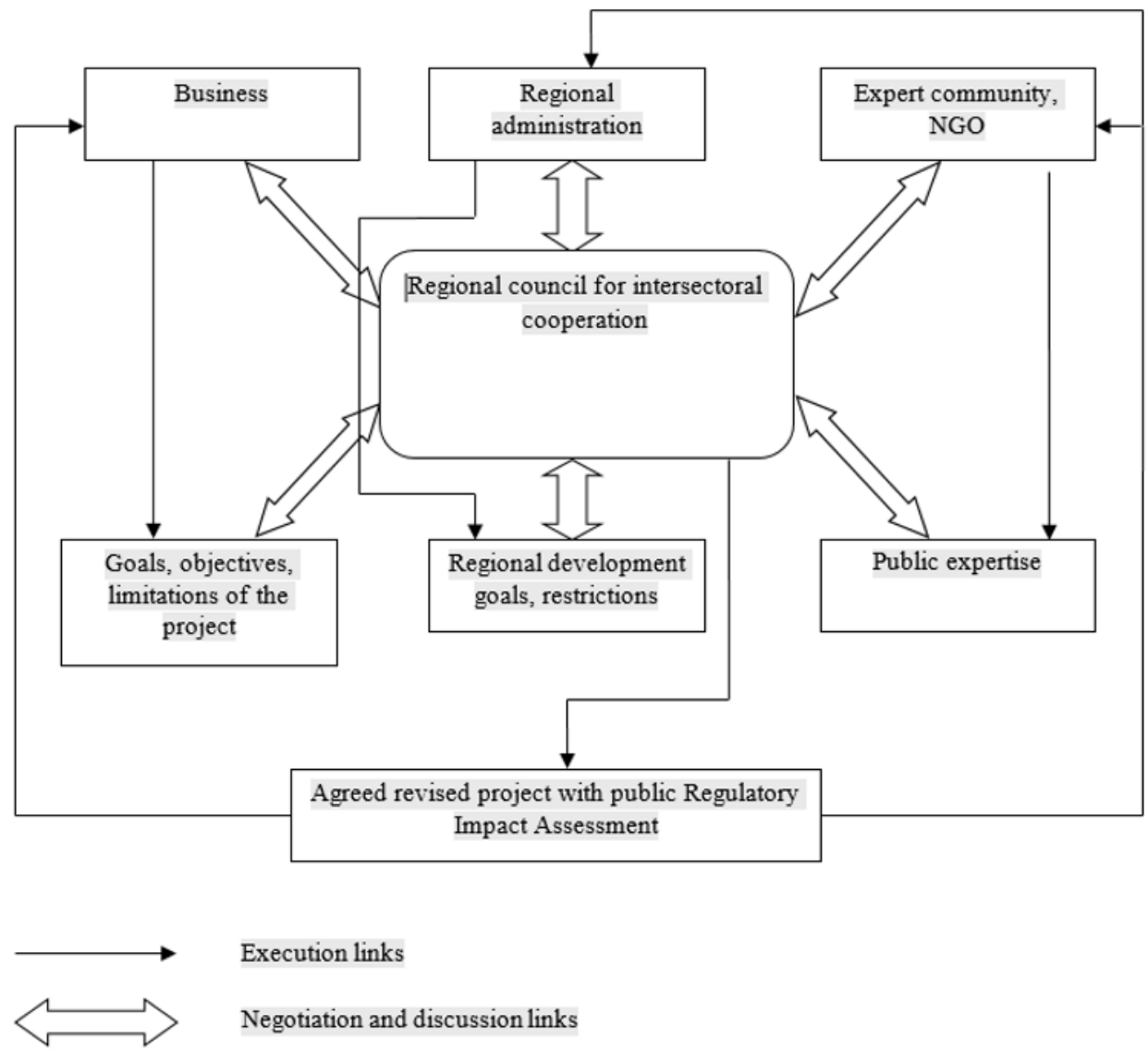

Fig.1. Methodology for creating a regional council for intersectoral cooperation.

As a result of such interaction of all three sectors of the economy, the role of civil society institutions increases, the existing contradictions move from the lobbies to the open information space, which allows finding compromise solutions by attracting outside experts based on the best world practices. Thus, the methodology of the regional council on intersectoral interaction not only allows achieving social balance and more efficient implementation of various projects, but also significantly increases the competence of business leaders and regional managers by attracting the scientific and professional community.

The development of the Council's methodology for intersectoral interaction seems important for another reason. Oil industry companies are budget-forming structures in many regions, which means that the indicators of socio-economic development of entire subjects of the Federation depend on the efficiency of their activities. For this reason, these business structures should plan their development, operational and strategic activities, taking into account the existing strategies for the development of territories. Currently, this is not always the case. In a situation where the parent company is located in Moscow or St. Petersburg, and subsidiaries operate in the regions, the activities of the latter are mainly aimed at fulfilling corporate goals and objectives and achieving certain performance indicators.

In fig. 2 there is a schematic representation of the environment in which a subsidiary of any oil company operates. 


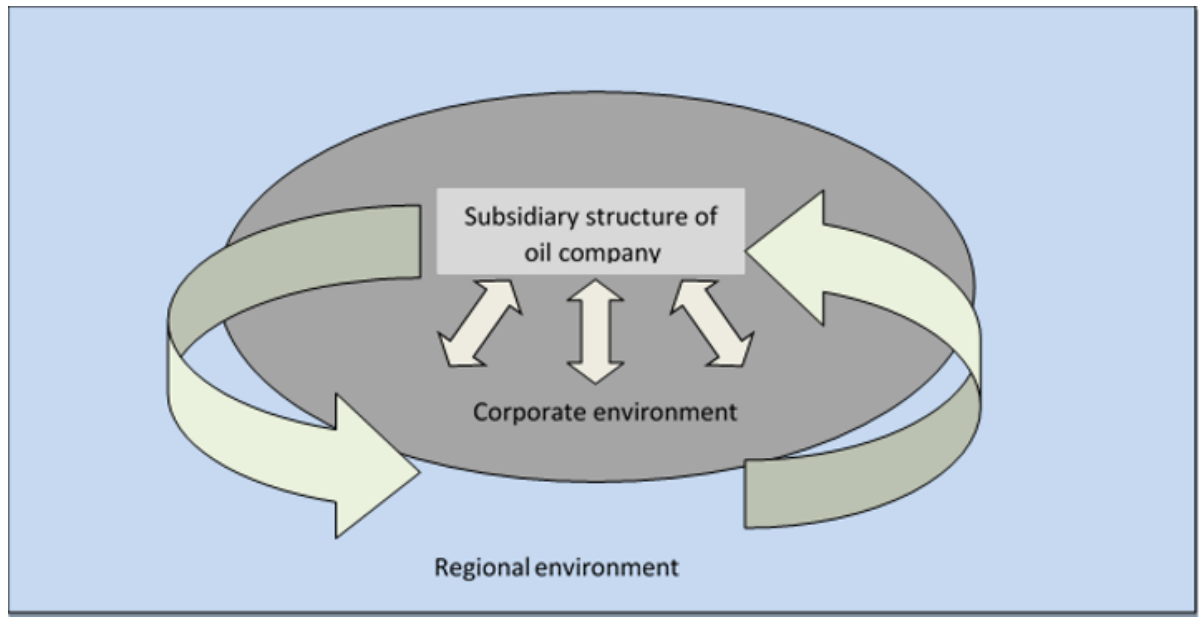

Fig.2. Operating environment of a subsidiary of an oil company.

As can be seen from the figure, the regional environment in any case has a significant impact on the functioning of any division of any federal or transnational company. This happens for a number of reasons. First, a number of issues related to ecology and effective natural resource management are within the jurisdiction of the constituent entities of the Russian Federation. Secondly, despite the legal affiliation of the company and the location of its head office, its economic indicators depend on the efficiency of its functioning "on the ground" in the immediate production regions. And the residents of these territories associate environmental and other negative consequences not with the activities of the federal authorities that issued the license, but with the low quality of the region's governance.

For these reasons, business and regional administrations are interested in finding an effective mechanism for interaction to minimize negative consequences and form realistic plans for the development of territories.

It is obvious that the development of concepts and strategies for regional development should take place in close interaction of similar business structures and regional administrations, which practically does not happen in modern conditions. Often in the regions, there is an inconsistent position of business and government on key issues of territorial development, and the long-term plans and strategies of companies do not correspond to the long-term development plans of the regions. To eliminate such an imbalance, it is proposed to use a model of interaction between subsidiaries of oil companies and regional administrations in the process of developing and implementing a long-term development strategy for a constituent entity of the Russian Federation.

\section{Conclusion}

The proposed model, taking into account the implementation of the methodology of the council for intersectoral interaction, will make it more transparent and informative to link the goals and objectives of corporations represented in the region by their subsidiaries with the goals and objectives of regional business, public structures and administration. The model takes into account all procedures for the approval and implementation of corporate and regional strategies, both in the short and long term.

So, in the process of forming an operational plan for the development of a territory or an annual budget, the regional administration will be able to more accurately predict the revenue side due to the information received from business structures. When using this model, all 
changes, procedures for reorganization and business restructuring will already be included in the plan, which will allow for a more detailed and professional consideration of possible risks and consequences of corporate decisions. Of course, the use of this model cannot protect against sudden negative events, "black swans" such as military conflicts, outbreaks of diseases, etc., however, it significantly increases the quality of the forecasts.

In the proposed model, short-term and long-term forecasts of business and the region are brought to different stages in a single life cycle of the territory development strategy. So, on the basis of current operational data on the budget execution of a business structure or region, a logical chain of further medium-term and long-term planning is built, and with the linking of these indicators, which is not observed in real life.

Thus, an efficiently built system of intersectoral interaction with the inclusion of all interested parties - from environmental non-profit organizations to the professional expert community - will minimize the negative consequences of decisions made, as well as reduce the risks of conflicts and level out contradictions between business structures and power elites.

\section{References}

1. M. Benassi, M. Landoni, Industry and Innovation 1, 1 (2015)

2. M. Brunet, Int. J. of project management 13, 1 (2018)

3. A. Cuervo-Cazurra, A. Inkpen, A. Musacchio, K. Ramaswamy, J. of Business Studies 45, 919 (2014)

4. S. Estrin, K.E. Meyer, B.B. Nielsen, S. Nielsen, J. of World Business, 31, 1 (2014)

5. M. Forbes, L.E.JR. Lynn, J. of Puvlic Administration Research and Theory, 559 (2005)

6. X. Huang, Asian Pacific Economic Literature 6, 1 (2018)

7. N.W. Leung, M.-A. Cheng, China J. of Accounting Research, 1 (2013)

8. D. Palcic, E. Reeves, State-owned Enterprise Policy and the Loss of Economic Sovereignty: The Case of Ireland. Public Organization Review, 117 (2013)

9. W. Shi, R.E. Hoskisson, Y.A. Zhang, Wiley Online Library 6, 13 (2016)

10. M.C. Thurber, D.R. Hults, P.R.P. Heller, Energy Policy 39, 5366 (2011) 